\title{
Apple Proliferation Resistance in Apomictic Rootstocks and Its Relationship to Phytoplasma Concentration and Simple Sequence Repeat Genotypes
}

\author{
C. Bisognin, B. Schneider, H. Salm, M. S. Grando, W. Jarausch, E. Moll, and E. Seemüller
}

First and fourth author: IASMA Research Center, I-38010 San Michele all'Adige (TN), Italy; second, third, and seventh authors: Federal Biological Research Centre for Agriculture and Forestry, Institute for Plant Protection in Fruit Crops, D-69221 Dossenheim, Germany; fifth author: AlPlanta-Institute for Plant Research, RLP AgroScience GmbH, D-67435 Neustadt/W., Germany; and sixth author: Federal Biological Research Centre for Agriculture and Forestry, Central Data Processing Group, D-14532 Kleinmachnow, Germany. Accepted for publication 4 September 2007.

\section{ABSTRACT}

Bisognin, C., Schneider, B., Salm, H., Grando, M. S., Jarausch, W., Moll, E., and Seemüller, E. 2008. Apple proliferation resistance in apomictic rootstocks and its relationship to phytoplasma concentration and simple sequence repeat genotypes. Phytopathology 98:153-158.

In an effort to select and characterize apple rootstock resistant to apple proliferation (AP), progenies from seven apomictic rootstock selections and their parental apomictic species, Malus sieboldii and M. sargentii, were compared to standard stocks M 9 and M 11. Seedlings derived from open pollinated mother plants were grafted with cv. Golden Delicious and grown under natural infection conditions. The progenies differed greatly in resistance to the AP agent 'Candidatus Phytoplasma mali'. Progenies of M. sieboldii and its descendent rootstock selections D2212, 4608, 4551 , and D1131 showed a high level of resistance, whereas progenies of $M$. sargentii and its descendent selections D1111 and C1828 proved susceptible. M 9 and M 11 showed an intermediate level of resistance. Phytoplasma titer in roots of the M. sieboldii and M. sargentii progeny groups was similarly low, whereas the concentration in the standard stocks was 100 to 5,000 times higher. In trees on most of the resistant stocks, only a minority was colonized in the scion, while in trees on susceptible and standard stocks, infection rate was often higher. Also, the titer in the top of trees on resistant stocks was usually lower than in trees on susceptible and standard stocks. Four progenies derived from open pollinated $M$. sieboldii and $M$. sieboldii descendents were subjected to DNA typing using simple sequence repeat (SSR) markers. This study revealed that the selected groups consisted mainly of mother-like plants (apomicts) and type I hybrids (unreduced mother genotype plus one male allele at each locus). Type II hybrids (full recombinants) and autopollinated offspring were rare. In the 4608 progeny, trees grown on type I hybrid rootstocks were significantly less affected than trees on motherlike stocks. In other progenies with fewer or no type I hybrids, trees on type II hybrids and autopollinated offspring suffered considerably more from disease than trees on mother-like stocks.
Phytoplasmas are wall-less bacteria of the class Mollicutes that cause diseases in more than a thousand plant species (21). Many of these diseases are of great economic importance. In Europe, one of the most damaging phytoplasma diseases is apple proliferation (AP) that is present in several major fruit growing areas and is caused by 'Candidatus Phytoplasma mali' (25). The pathogen induces a range of symptoms that are either specific such as witches'-brooms, enlarged stipules, and rosettes, or nonspecific such as foliar reddening and yellowing, growth suppression, and undersized, unmarketable fruits. AP is mainly spread by the psyllids Cacopsylla picta and C. melanoneura $(6,11,27)$. The leafhopper Fieberiella flori is also reported to vector the pathogen (14). Furthermore, infection via root bridges is possible (4).

AP is difficult to control. Phytosanitary measures such as the use of healthy planting material and uprooting diseased trees are often not satisfactory as new infections do occur. The results obtained with insecticide application against insect vectors are contradictory. According to Kunze (15) infection rate can be kept at a low level by regular chemical treatments while reduced insecticide programs do not provide satisfactory control. More recent experiments carried out in northern Italy showed that frequent,

Corresponding author: E. Seemüller; E-mail address: e.seemueller@bba.de

doi:10.1094/PHYTO-98-2-0153

This article is in the public domain and not copyrightable. It may be freely reprinted with customary crediting of the source. The American Phytopathological Society, 2008. well-timed treatments do not always sufficiently reduce disease spread (L. Mattedi and W. Jarausch, unpublished data).

The most promising approach to control AP appears to be the use of resistant plants. Previous work has shown that ' $\mathrm{Ca}$. P. mali' is eliminated in the stem during winter due to degeneration of phloem sieve tubes. Overwintering occurs in the roots where functional sieve tubes are present throughout the year. From the roots the stem may be recolonized in spring when new phloem is being formed $(17,19,24)$. This fluctuation in the colonization pattern has led to the presumption that growing scion cultivars on resistant rootstocks can prevent the disease or reduce their impact.

However, extensive studies with many established and experimental rootstocks, which were mainly based on Malus $\times$ domestica, have shown that there is no satisfactory resistance in this group. They frequently develop symptoms, remain permanently infected and show, as estimated by 4,6-diamidino-2-phenylindole (DAPI) fluorescence staining, a high phytoplasma titer (22). Screening of a large number of other Malus taxa revealed that they are often more susceptible to infection than $M . \times$ domestica genotypes. Many of them showed a high mortality rate. Resistance was observed in some experimental rootstock selections derived from crossings between the apomictic species $M$. sieboldii and genotypes of the nonapomictic species $M . \times$ domestica or $M$. purpurea. In preliminary trials, resistance was also observed in progenies of similar crossings with M. sargentii. Resistant plants either never developed symptoms or recovered within a few years. In these genotypes the pathogen was not detected or 
was difficult to detect by fluorescence microscopy, indicating a low phytoplasma titer $(12,22)$.

Apomixis is asexual reproduction characterized by the formation of seeds that are genetically identical usually to the female parent. It occurs in several plant families including the Rosaceae. In the genus Malus apomixis is, among others, present in the tetraploid Asian species M. sieboldii and M. sargentii. However, apomixis is not obligate in these species. Progenies from open pollination contain a variable percentage of hybrids from unreduced and reduced maternal gametes. For example, from a tetraploid apomictic female parent and a diploid nonapomictic male parent, pentaploid hybrids are obtained from unreduced female gametes having an allele at each locus segregating from the male parent. Triploid recombinants result when both gametes are reduced $(3,20)$. Attempts to develop apomictic rootstocks were undertaken for easy propagation by seeds, virus-free plants, better anchorage, and higher resistance to some fungal and bacterial diseases than dwarfing $M . \times$ domestica-derived stock (20).

Based on the results obtained in previous work (12,22), a field trial under standard growing conditions was established in which experimental apomictic rootstocks were compared with $M . \times d o-$ mestica-type rootstocks M 9 and M 11. Whereas in previous trials the trees were graft-inoculated, one objective of this trial was to evaluate the trees under natural infection conditions in order to avoid impairment of the test by a limited strain spectrum or an inoculum dose that is much higher than when infections occurred by insects. Also, to make sure that the infection rate is high and that there is sufficient time for disease development, the trial was planned to be observed for much longer than in previous trials. In the course of this trial, new technologies became available that allowed more sophisticated studies of phytoplasma resistance. These included quantitative real-time PCR (q-PCR) with which the phytoplasma titer can be determined much more sensitively and precisely than by using the previously employed DAPI fluorescence microscopy. Another new technique employed was DNA typing using simple sequence repeat (SSR) markers with which the various classes of allele combinations in apomictic progenies can be determined (3).

\section{MATERIALS AND METHODS}

Plant material and disease rating. Seedling progenies from seven experimental apomictic rootstock selections (Table 1) and their apomictic parents $M$. sieboldii and M. sargentii were obtained from H. Schmidt, formerly Bundesanstalt für Züchtungsforschung an Kulturpflanzen, Ahrensburg, Germany. Clonal standard stocks M 9 and M 11 were included in the study. The seedling progenies and standard stocks were grown in the nursery and budded with cv. Golden Delicious. In spring of 1993, 14 to 35 trees of each rootstock-scion combination were transplanted to the field in a randomized block design consisting of two to five replicates. Maintenance including plant protection measures was similar to that of commercial orchards. From 1994 to 2005 foliar symptoms and terminal growth of the trees were recorded annually in late summer/early fall using a rating system from 0 to 3. Symptom rating categories were: slight reddening or mild yellowing $=0.5$; severe reddening and yellowing, premature leaf drop, leaf roll, and enlarged stipules $=1$; reduced vigor $=2$; witches'-brooms, undersized fruits, and severe stunting $=3$. Mortality was rated as a 10 . At the end of the observation period the highest annual ratings of each tree were added so that accumulated disease indices were obtained. In addition the occurrence of undersized fruits was recorded over 10 years. The years of appearance were accumulated to obtain the value per tree.

DNA extraction and qPCR. From each tree examined, samples from three different roots and current season's shoots were collected in early fall of 2005. Phloem from healthy and infected trees was prepared as described (1) and DNA was extracted from 0.2 to $0.8 \mathrm{~g}$ of phloem tissue according to Doyle and Doyle (5). The nucleic acid pellets were suspended in $500 \mu \mathrm{l}$ of sterile water. Quantitative PCR was performed with a Bio-Rad iCycler IQ. The amplification was performed in 50- $\mu$ l reactions containing 25 pmol of each primer (fAT 5'-CATCATTTAGTTGGGCACTT-3', rATRT 5'-CGCTTCAGCTACTCTTTGTG-3'), 2 pmol Taqman probe (5'-CCCTTATGACCTGGGCTACA-3') with a reporter fluorescence dye (FAM) at the $5^{\prime}$ end and a quencher dye (TAMRA) at the $3^{\prime}$ end, $0.2 \mathrm{mM}$ of each dNTP, $1 \mathrm{U}$ heat stable polymerase (Tempase, Amplicon), $1 \times$ polymerase buffer and $5 \mu \mathrm{l}$ of DNA. The following parameters were used for amplification: $30 \mathrm{~min}$ at $95^{\circ} \mathrm{C}$ followed by a two-step protocol consisting of 41 cycles at $95^{\circ} \mathrm{C}$ for $15 \mathrm{~s}$ and $56^{\circ} \mathrm{C}$ for $1 \mathrm{~min}$. The samples were run in duplicates. Calculation of phytoplasma titer was by means of a cloned AP phytoplasma 16S rRNA gene standard dilution ranging from $10^{6}$ to $10^{1}$ copies. Sample values distinctly higher than that of control DNA from healthy trees maintained under insect-proof conditions were considered as phytoplasma positive.

Microsatellite analysis. The progenies of $M$. sieboldii and apomictic selections D2212, 4551, and 4608 were DNA typed using SSR markers in order to establish their pedigree. DNA was extracted as described above. Twelve pairs of oligonucleotide primers were used: CH01f03b, CH01g05, Ch02a08, CH02b1, $\mathrm{CH02c02a,} \mathrm{CH02c11,} \mathrm{CH03d02,} \mathrm{CH04e03,} \mathrm{and} \mathrm{CH04g07}(7,16)$, and GD96, GD142, and GD147 (8-10). This set of microsatellites was chosen based on the high level of heterozygosity in the above Malus accessions. PCR was performed in a $15-\mu \mathrm{l}$ volume containing 50 to $100 \mathrm{ng}$ of genomic DNA, $0.2 \mathrm{U}$ of AmpliGold Taq polymerase (Applied Biosystem), 1× GeneAmp PCR Buffer II, $1.5 \mathrm{mM} \mathrm{MgCl}$ with primers " $\mathrm{CH}$ " or $2.2 \mathrm{mM}$ with the others primers, $0.2 \mathrm{mM}$ dNTPs and $0.3 \mu \mathrm{M}$ of each primer pair. Reverse primers were fluorescently labeled with Dye Phosphoramidities (HEX, 6-FAM, and NED). PCR was carried out using the Gene Amp PCR System 9700 (Perkin Elmer) with three different programs. Amplification with primers " $\mathrm{CH}$ " was performed for 33 cycles at the following conditions: initial denaturation at $95^{\circ} \mathrm{C}$ for $10 \mathrm{~min}, 95^{\circ} \mathrm{C}$ for $30 \mathrm{~s}, 60^{\circ} \mathrm{C}$ for $30 \mathrm{~s}, 72^{\circ} \mathrm{C}$ for $60 \mathrm{~s}$, and final extension at $72^{\circ} \mathrm{C}$ for $7 \mathrm{~min}$. Amplification with primers "GD" was performed for 25 cycles at the following conditions: initial denaturation at $95^{\circ} \mathrm{C}$ for $10 \mathrm{~min}, 95^{\circ} \mathrm{C}$ for $60 \mathrm{~s}, 55^{\circ} \mathrm{C}$ for $120 \mathrm{~s}$, $72^{\circ} \mathrm{C}$ for $120 \mathrm{~s}$, and a final extension of $7 \mathrm{~min}$ at $72^{\circ} \mathrm{C}$. Amplification with primer "02b1" was performed for 35 cycles at the following conditions: initial denaturation at $95^{\circ} \mathrm{C}$ for $10 \mathrm{~min}$, $95^{\circ} \mathrm{C}$ for $40 \mathrm{~s}, 50^{\circ} \mathrm{C}$ for $40 \mathrm{~s}, 72^{\circ} \mathrm{C}$ for $20 \mathrm{~s}$, and final extension at $72^{\circ} \mathrm{C}$ for $7 \mathrm{~min}$. Separation and sizing of SSR alleles were per-

TABLE 1. Parentage of apomictic rootstocks examined

\begin{tabular}{|c|c|c|}
\hline Rootstock & Parentage & Ploidy \\
\hline D2212 & $(M . \times$ domestica $\mathrm{cv}$. Laxton's Superb $\times$ M. sieboldii $)$, open pollinated & $4 n$ \\
\hline 4608 & M. purpurea $\mathrm{cv}$. Eleyi $\times M$. sieboldii & $3 n$ \\
\hline 4551 & M. $\times$ domestica $\mathrm{cv}$. Laxton's Superb $\times$ M. sieboldii & $3 n$ \\
\hline D1131 & (M. sieboldii $\times$ M. $\times$ domestica $\mathrm{cv}$. Pigeon), open pollinated & $4 n$ \\
\hline 20186 & M. purpurea $\mathrm{cv}$. Eleyi $\times$ M. sieboldii & $3 n$ \\
\hline D1111 & M. sargentii $\times$ M. $\times$ domestica $\mathrm{cv}$. Filippa & $3 n$ \\
\hline $\mathrm{C} 1828$ & M. sargentii $\times M . \times$ domestica 'Niedzwetzkyana' & $3 n$ \\
\hline
\end{tabular}


formed on a 3100 ABI Prism apparatus (Applied Biosystems) and analysis was carried out with softwares Gene Scan 2.1 and Genotyper using Gene Scan 500 ROX as size standard (Applied Biosystems). Use of three dye colors allowed automated detection of fragments arising from multiple loci within one lane simultaneously (multiplexing).

Statistical analysis. The differences between means were tested for significance using the Tukey test with a significance level of $P=0.05$. No statistical comparison of data was attempted when sample numbers appeared insufficient.

\section{RESULTS}

Level of resistance. Most trees showed symptoms for the first time between the first and the fifth year of observation. Only 10 out of a total of 287 trees never developed symptoms. Evaluation of the data obtained from disease ratings revealed that the rootstocks examined differed considerably in resistance to AP as expressed by the cumulative disease indices and the cumulative undersized fruit values (Table 2). Progenies of $M$. sieboldii and M. sieboldii-derived apomicts 4608, 4551, D1131, and D2212, (in the following referred to as "resistant $M$. sieboldii-derived progenies") responded similarly and showed a high level of resistance. In contrast, progenies from $M$. sieboldii-derived selection 20186, M. sargentii and M. sargentii-based selections D1111 and C1828, proved susceptible. Standard rootstocks M 9 and M 11 showed an intermediate position. The low level of resistance in the susceptible apomicts is also evident from the mortality rate as in each of the progenies of $M$. sargentii, selections 20186 and D1111, three trees died, and in the C1828 progeny, six trees. Also, two trees on M 9 declined. There was no mortality in the resistant
M. sieboldii-derived progenies. Moreover, witches'-broom, the most typical symptom, was never observed in trees of this group, in contrast to M 11 where brooms occurred repeatedly.

In all root-scion combinations considerable variability in resistance was observed. However, there were great quantitative differences (Table 2). On resistant $M$. sieboldii-derived progenies $80 \%$ or more of the trees were not or only slightly affected by showing disease indices between 0 and 8.0. For trees on standard stocks and, in particular, on susceptible apomicts, this percentage was considerably lower, ranging from $68 \%$ for M 11 to $25 \%$ for C1828.

Phytoplasma concentration. Six to nine affected trees from each kind of rootstock were selected to determine the phytoplasma titer in roots and current season's shoots. In the roots all but one tree on M 9 proved to be infected (Table 3). Phytoplasma concentrations in the apomictic rootstocks were, irrespective of the level of resistance, in the same range, and did not differ significantly. However, in standard stocks M 9 and M 11, the means were 100 to more than 5,000 times higher than in the apomicts. In shoots of trees grown on $M$. sieboldii and on $M$. sieboldii-derived stocks, $M$. sargentii and $\mathrm{M} 9$, the infection rate in the scion was much lower than in the root. Furthermore, the phytoplasma titer in the few infected scions of resistant stocks was lower than in the roots, although scion cultivar Golden Delicious is a high titer host. On the other hand, nearly all trees on $M$. sargentii-derived rootstock selections and $\mathrm{M} 11$ were infected in the shoots, which showed mostly a higher phytoplasma concentration than shoots from resistant apomicts. Only a minority of the shoot-infected trees (1 out of 9) of the resistant $M$. sieboldii-derived progenies showed symptoms in the year of sampling whereas the majority of trees on the remaining stocks (13 out of 23 ) was symptomatic.

TABLE 2. Apple proliferation resistance of apomictic rootstocks in comparison to apomictic parents and standard rootstocks

\begin{tabular}{lcccc}
\hline Rootstock & No. of trees examined & Cumulative disease index/tree $^{\mathrm{w}}$ & ${\text { Slightly affected trees }(\%)^{\mathrm{x}}}$ & Undersized fruits (cumulative value/tree) $^{\mathrm{y}}$ \\
\hline 4608 & 28 & $4.0 \mathrm{a}^{\mathrm{z}}$ & 83 & $0.21 \mathrm{a}^{\mathrm{z}}$ \\
D2212 & 35 & $4.3 \mathrm{a}$ & 80 & $0.25 \mathrm{a}$ \\
4551 & 28 & $4.9 \mathrm{a}$ & 83 & $0.28 \mathrm{a}$ \\
D1131 & 28 & $5.0 \mathrm{a}$ & 82 & $0.46 \mathrm{a}$ \\
M. sieboldii & 28 & $5.2 \mathrm{a}$ & 83 & $0.36 \mathrm{a}$ \\
M 11 & 28 & $7.2 \mathrm{a}, \mathrm{b}$ & 68 & $0.57 \mathrm{a}$ \\
M 9 & 28 & $8.3 \mathrm{a}, \mathrm{b}$ & 64 & $1.46 \mathrm{~b}, \mathrm{c}$ \\
20186 & 28 & $10.3 \mathrm{~b}, \mathrm{c}$ & 57 & $1.43 \mathrm{~b}, \mathrm{c}$ \\
D1111 & 14 & $10.8 \mathrm{~b}, \mathrm{c}$ & 57 & $1.50 \mathrm{~b}, \mathrm{c}$ \\
M. sargentii & 21 & $11.0 \mathrm{~b}, \mathrm{c}$ & 43 & $2.19 \mathrm{~d}$ \\
C1828 & 21 & $13.2 \mathrm{c}, \mathrm{d}$ & 25 & $1.95 \mathrm{c}, \mathrm{d}$ \\
\hline
\end{tabular}

${ }^{\mathrm{w}}$ Annual disease ratings accumulated over 12 years.

${ }^{x}$ Trees with cumulative disease index $\leq 8.0$.

y Occurrence of small fruit symptom accumulated over 10 years.

${ }^{\mathrm{z}}$ Values with the same letter are not significantly different from each other at $P=0.05$.

TABLE 3. Phytoplasma concentrations in phloem preparations from roots and shoots of trees on apomictic and standard rootstocks

\begin{tabular}{|c|c|c|c|c|}
\hline \multirow[b]{2}{*}{ Rootstock } & \multicolumn{2}{|c|}{ Phytoplasmas in roots } & \multicolumn{2}{|c|}{ Phytoplasmas in shoots } \\
\hline & Phytoplasma-positive trees ${ }^{x}$ & $\begin{array}{l}\text { Phytoplasma concentration } \\
\text { (cells/g of phloem })^{\mathrm{y}}\end{array}$ & Phytoplasma-positive scions ${ }^{\mathrm{x}}$ & $\begin{array}{l}\text { Phytoplasma concentration } \\
\text { (cells/g of phloem })^{\mathrm{y}}\end{array}$ \\
\hline $\mathrm{D} 2212$ & $7 / 7$ & $2.2 \times 10^{5} \mathrm{a}^{\mathrm{z}}$ & $2 / 6$ & $1.3 \times 10^{5}$ \\
\hline 4551 & $6 / 6$ & $1.2 \times 10^{6} \mathrm{a}$ & $1 / 6$ & $2.2 \times 10^{4}$ \\
\hline D1131 & $8 / 8$ & $2.8 \times 10^{6} \mathrm{a}$ & $4 / 6$ & $7.6 \times 10^{4}$ \\
\hline M. sieboldii & $6 / 6$ & $1.1 \times 10^{6} \mathrm{a}$ & $1 / 6$ & $2.6 \times 10^{5}$ \\
\hline $\mathrm{C} 1828^{\circ}$ & $7 / 7$ & $3.3 \times 10^{5} \mathrm{a}$ & $6 / 6$ & $4.9 \times 10^{6}$ \\
\hline M 9 & $6 / 7$ & $8.7 \times 10^{8} \mathrm{~b}$ & $2 / 6$ & $1.6 \times 10^{7}$ \\
\hline M 11 & $6 / 6$ & $1.4 \times 10^{9} \mathrm{c}$ & $6 / 6$ & $1.3 \times 10^{9}$ \\
\hline
\end{tabular}

${ }^{x}$ Numerator, number of phytoplasma-positive trees; denominator, total trees tested.

${ }^{y}$ Average of infected trees.

${ }^{\mathrm{z}}$ Values with the same letter are not significantly different from each other at $P=0.05$. 
To examine possible correlations between disease severity and phytoplasma titer, the phytoplasma concentrations in not or slightly (disease index $\leq 8$ ) and in moderately to severely affected trees (disease index $>8$ ) were compared. In most rootstocks the titer in moderately to severely affected trees was similar to or higher than in trees that did not suffer or were slightly affected by the disease. However, in rootstocks 4608 and 20168, slightly affected trees showed higher values than moderately to severely affected trees. The higher mean of the latter group was, across all rootstocks, statistically significant at $P=0.05$ (data not shown).

SSR genotyping and resistance. Four apomictic, $M$. sieboldiiderived progenies were subjected to SSR genotyping. Based on the allele patterns obtained, the plants were assigned to four different classes: "mother-like" when the SSR profile was identical to the female parent, "type I hybrid" when in addition to the unreduced mother genotype one male allele was observed at each locus, "type II hybrid" when both parents contributed with a half of their genotype, and "autopollinated" when SSR patterns were consistent with selfing events (Fig. 1, Table 4). As expected for apomicts, mother-like plants were predominant in all progenies, comprising $65 \%$ of the plants across the progenies. The other

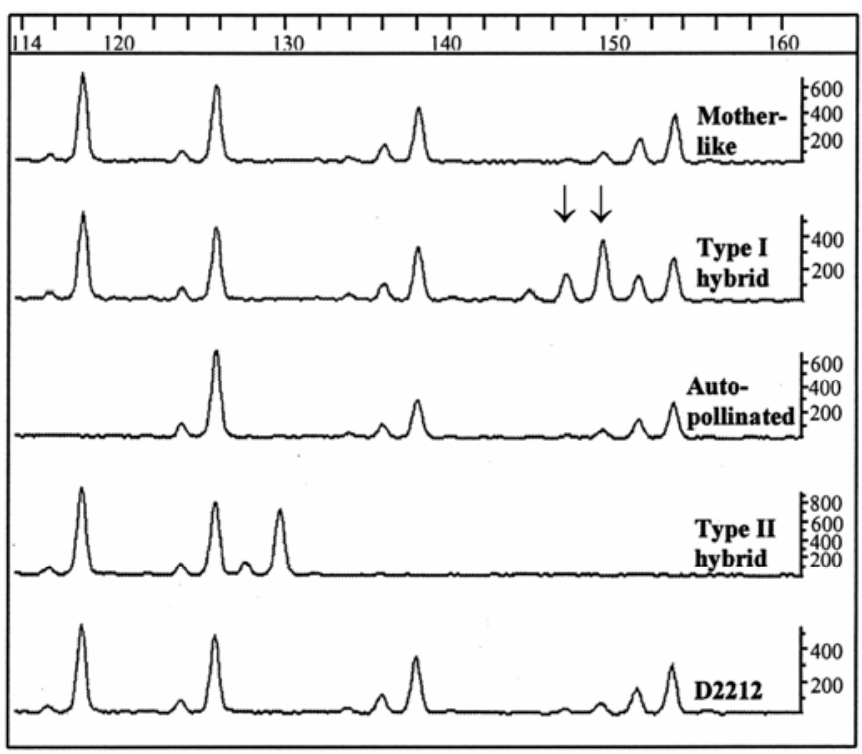

Fig. 1. Example of fluorescence profiles of amplified fragments of simple sequence repeats (SSR) locus GD147 of apomictic selection D2212 and four progeny plants resulting from open pollination. Four progeny classes can be distinguished. The fragment size (in base pairs) of the amplified fragments is shown at the top. Fluorescence intensity is shown on the right side. Arrows indicate the peaks contributed by the unknown male parent to the type I hybrid profile. classes were represented differently. Type I hybrids occurred in substantial numbers only in the progenies of apomicts 4551 and 4608. These trees were markedly less affected than trees on mother-like rootstocks. However, only the differences in the 4608 progeny were statistically significant. The differences observed were mainly due to the fact that 4 and 5 trees on mother-like stocks of 4608 on 4551 , respectively, were moderately to severely affected by showing disease indices between 8.8 and 21.5. In contrast, the highest disease index of type I hybrid-grown trees was 7.0. In the progenies of D2212 and M. sieboldii, trees on motherlike roots were considerably less affected than trees on stocks derived from hybridization or selfing. While on motherlike stocks 4 and $25 \%$, respectively, were moderately to severely affected, the values for stocks derived from hybridization or selfing ranged between 50 and $67 \%$. The differences in phytoplasma titer between the various genotypes of the progenies examined were relatively small and in no case statistically significant.

\section{DISCUSSION}

The rootstocks examined differed significantly in resistance to AP. In decreasing order of resistance, three major groups could be distinguished that consisted of (i) progenies of $M$. sieboldii and the resistant $M$. sieboldii-derived selections, (ii) standard stocks M 9 and M 11, and (iii) progenies of M. sargentii, M. sargentiibased selections, and selection 20186. The first group had a high level of resistance as expressed by low disease ratings, a high percentage of healthy-appearing or slightly affected trees, and a very rare occurrence of undersized fruits, the economically most important impact of the disease. In all these disease categories the resistant group showed better values than the standard stocks although the differences were not always statistically significant. Of particular importance is the significantly lower occurrence of undersized fruits than of trees on $\mathrm{M} 9$, the major commercial rootstock in Europe. Despite the better resistance of the members of the resistant group in comparison to standard stocks, they were not fully satisfactory from the agronomical point of view. Their major disadvantage is that they are often too vigorous, tend to alternate bearing, and mediate lower yields than M 9 (E. Seemüller, unpublished data). Thus, further selection and/or breeding is required to obtain suitable resistant stocks for commercial apple growing. Such work has to be based on the resistance of $M$. sieboldii, the only known source of AP resistance.

Considerable differences in disease severity were observed in all rootstocks. In case of clonal stocks $M 9$ and $M$ 11, this variation may be explained by differences in virulence of the infecting phytoplasma. Recent work has shown that phytoplasma strains differ strongly in this respect and that about one third of the strains is either avirulent to weakly virulent, moderately virulent, or severely virulent (26). Differences in strain virulence are

TABLE 4. Disease ratings and phytoplasma concentrations in relation to simple sequence repeat (SSR) genotypes

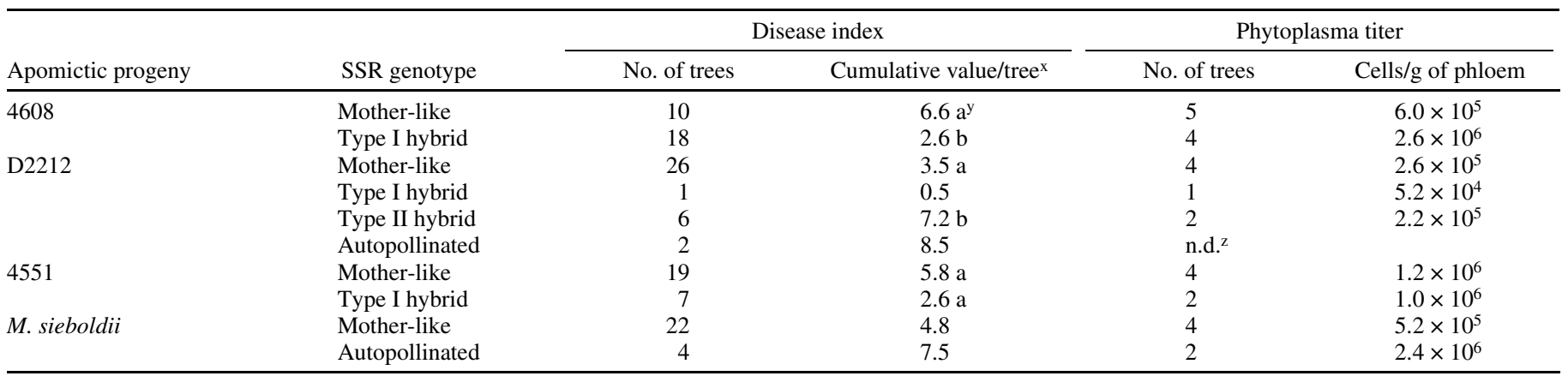

${ }^{x}$ Annual disease ratings accumulated over 12 years.

${ }^{y}$ Values with the same letter within the same progeny are not significantly different from each other at $P=0.05$. Other values were not tested due to too low sample numbers.

${ }^{z}$ Not done. 
without doubt also involved in the variability of apomicts. As in the apomicts examined four different combinations of the parental genetic contribution were deduced from SSR profiles; these genetic differences appeared to also account for variation. It could be shown that in the progenies of the triploid selections 4608 and 4551 trees on mother-like plants were more severely affected than trees on type I hybrids. This phenomenon may be due to the unknown genetic contribution of the male parent. On the other hand the higher variation of disease severity of trees on motherlike stocks than on type I hybrids may be due to their lower level of resistance. This may result in a wider range of symptoms following infection by differently virulent phytoplasma strains than in trees on the more resistant type I hybrids. The fact that trees on type II hybrids of selection D2212 showed higher susceptibility than trees on mother-like stocks indicate segregation of the resistance trait of a susceptible male parent. Also, the low level of resistance of trees on autopollinated stocks may be due to recombination at resistance loci. These observations are the first molecular data on AP resistance, which will be valuable for future studies on the inheritance of AP resistance and for breeding work. Furthermore, the variation within progenies from apomicts indicates that such progenies, like seedlings from nonapomictic plants, are unsuitable for being used as rootstocks. Rather, suitable genotypes have to be carefully selected and then vegetatively propagated.

Virtually all trees examined became naturally infected during the observation period as evidenced by the presence of phytoplasmas in the roots. However, phytoplasma concentrations in the roots differed considerably. There were two categories, the hightiter M. $\times$ domestica-based stocks M 9 and M 11 and the low-titer progenies of apomictic rootstock selections and their apomictic parents. Within the latter group there were no significant differences in phytoplasma titer although $M$. sieboldii- and $M$. sargentii-derived stocks differed strongly in resistance. The latter group proved very susceptible, much more than the $M . \times$ domestica stocks. This indicates that host suitability per se, as expressed in phytoplasma titer, is obviously not the deciding factor for resistance. Instead it appears that the pathogenic effect of phytoplasma infection is of qualitative rather than quantitative nature. This may be explained by the fact that the phloem residing phytoplasmas cause formation of callose, sieve tube necrosis, and depletion of starch in the roots of susceptible genotypes of apple and pear $(2,13)$. In previous work it has been shown that a severely affected $M$. sargentii-derived apomict showed extended sieve tube necrosis together with a low starch level and a very low phytoplasma titer. On the other hand, two slightly affected plants, an $M . \times$ domestica-related genotype and a 4551-derived seedling, showed little phloem necrosis and high starch contents together with high and low phytoplasma concentration, respectively (13). This indicates that the response of the phloem to infection is an important factor in resistance and that this response is not markedly influenced by phytoplasma concentration. The AP resistance of Malus genotypes, as reported here, largely agrees with previous findings obtained following graft inoculation $(12,22)$. However, the high susceptibility of progenies of $M$. sargentiiderived apomicts C1828 and D1111 became evident only in this work after longer observation than in previous trials.

In contrast to the roots, only a minority of the trees was colonized in the top at the end of the observation period, although sampling was performed at a time when phytoplasma concentration was highest. Progenies showing low infection rates included mostly $M$. sieboldii-derived rootstocks. Also, the titer in the scion was in most cases lower than in the roots. Both findings were probably related to seasonal changes in the colonization patterns of the AP phytoplasma. Previous studies based on periodic grafting and DAPI fluorescence microscopy have shown that the pathogen persists during the winter in the roots from where recolonization of the scion may take place in spring when new phloem is being formed. However, because infected trees often did not develop symptoms and phytoplasmas could not be detected in the stem, it was concluded that recolonization does not occur every year, particularly when trees were older or infected for a longer time $(17,19,23,24)$. These findings obtained by examining trees on $M . \times$ domestica rootstocks are consistent with the results of this work in which the much more sensitive q-PCR technology was employed. With this approach we succeeded in detecting the very low phytoplasma concentrations usually present in the stem of trees on apomictic rootstocks. The low infection rate and the low titer in the stem of trees on resistant apomictic stocks seem to result from low phytoplasma concentrations in the roots. The low starting concentration in the roots and poor host suitability of apomictic genotypes may have a negative effect on the spread of the pathogen from the roots into the scion. Thus, the low titer in the roots is likely to contribute to the resistance of $M$. sieboldii-derived stocks. It is well established that severe symptoms such as witches'-brooms and undersized fruits are only developed when the phytoplasma concentration in the stem is high (18).

\section{ACKNOWLEDGMENTS}

The research was supported as part of the SMAP I and SMAP II projects by grants from the Provincia Autonoma di Trento and the Istituto Agrario di S. Michele all' Adige (Italy). We thank H. Schmidt for providing the apomictic seedlings used in this work.

\section{LITERATURE CITED}

1. Ahrens, U., and Seemüller, E. 1994. Detection of mycoplasmalike organisms in declining oaks by polymerase chain reaction. Eur. J. Forest. Pathol. 24:55-63.

2. Batjer, L. P., and Schneider, H. 1960. Relation of pear decline to rootstocks and sieve-tube necrosis. P. Am. Soc. Hortic. Sci. 76:85-97.

3. Bisognin, C., Jarausch, W., Seemüller, E., and Grando, M. S. 2004. Analisi del pedigree mediante marcatori SSR in progenie di melo ottenute da incrocio con specie apomittiche. Italus Hortus 10, Suppl. 4:242-245.

4. Ciccotti, A. M., Bianchedi, P. L., Bragagna, P., Deromedi, M., Filippi, M., Forno, F., and Mattedi, L. 2005. Trasmissione di apple proliferation tramite anastomosi radicali. Petria 15:169-171.

5. Doyle, J. J., and Doyle, J. L. 1990. Isolation of plant DNA from fresh tissue. Focus (BRL) 12:13-15.

6. Frisinghelli, C., Delaiti, L., Grando, M. S., Forti, D., and Vindimian, M. E. 2000. Cacopsylla costalis (Flor 1861), as a vector of apple proliferation in Trentino. J. Phytopathol. 148:425-431.

7. Gianfranceschi, L., Seglias, N., Tarchini, R., Komjanc, M., and Gessler, C. 1998. Simple sequence repeats for the genetic analysis of apple. Theor. Appl. Genet. 96:1069-1076.

8. Guilford, P., Prakash, S., Zhu, J. M., Rikkerink, E., Gardiner, S., Bassett, H., and Forster, R. 1997. Microsatellites in Malus $\times$ domestica (apple): Abundance, polymorphism and cultivar identification. Theor. Appl. Genet. 94:249-254.

9. Hemmat, M., Weeden, N., and Brown, S. 2003. Mapping and evaluation of Malus $\times$ domestica microsatellites in apple and pear. J. Am. Soc. Hortic. Sci. 128:515-520.

10. Hokanson, S. C., Szewc-McFadden, A. K., Lamboy, W. F., and Mc Ferson, J. R. 1998. Microsatellite (SSR) markers reveal genetic identity, genetic diversity and relationships in a Malus $\times$ domestica Borkh. core subset collection. Theor. Appl. Genet. 97:671-683.

11. Jarausch, B., Schwind, N., Jarausch, W., Krczal, G., Dickler, E., and Seemüller, E. 2003. First report of Cacopsylla picta as a vector of apple proliferation phytoplasma in Germany. Plant Dis. 87:101.

12. Kartte, S., and Seemüller, E. 1991. Susceptibility of grafted Malus taxa and hybrids to apple proliferation disease. J. Phytopathol. 131:137-148.

13. Kartte, S., and Seemüller, E. 1991: Histopathology of apple proliferation in Malus taxa and hybrids of different susceptibility. J. Phytopathol. 131:149-160.

14. Krczal, G., Krczal, H., and Kunze, L. 1988. Fieberiella florii (Stål), a vector of apple proliferation agent. Acta Hortic. 235:99-106.

15. Kunze, L. 1976: Spread of apple proliferation in a newly established apple plantation. Acta Hortic. 67:121-127.

16. Liebhard, R., Gianfranceschi, L., Koller, B., Ryder, C. D., Tarchini, R., Van De Weg, E., and Gessler, C. 2002. Development and characterisation of 140 new microsatellites in apple (Malus x domestica Borkh.). Mol. 
Breed. 10:217-241.

17. Schaper, U., and Seemüller, E. 1982. Condition of the phloem and the persistence of mycoplasmalike organisms associated with apple proliferation and pear decline. Phytopathology 72:736-742.

18. Schaper, U., and Seemüller, E. 1984. Effect of the colonization behavior of the apple proliferation and pear decline causal agents on their detectability by fluorescence microscopy. Nachrichtenbl. Deut. Pflanzenschutzd. 36:21-25. (in German)

19. Schaper, U., and Seemüller, E. 1984. Recolonization of the stem of apple proliferation and pear decline-diseased trees by the causal organisms in spring. Z. PflKrankh. PflSchutz 91:608-613.

20. Schmidt, H. 1988. Criteria and procedures for evaluating apomictic rootstocks for apple. HortScience 23:104-107.

21. Seemüller, E., Garnier, M., and Schneider, B. 2002. Mycoplasmas of plants and insects. Pages 91-116 in: Molecular Biology and Pathology of Mycoplasmas. S. Razin and R. Herrmann, eds. Kluwer Academic/Plenum Publishers, London.

22. Seemüller, E., Kartte, S., and Kunze, L. 1992. Resistance in established and experimental apple rootstocks to apple proliferation disease. Acta
Hortic. 309:245-251.

23. Seemüller, E., Kunze, L., and Schaper, U. 1984. Colonization behavior of MLO, and symptom expression of proliferation-diseased apple trees and decline-diseased pear trees over a period of several years. Z. PflKrankh. PflSchutz 91:525-532.

24. Seemüller, E., Schaper, U., and Zimbelmann, F. 1984. Seasonal variation in the colonization patterns of mycoplasmalike organisms associated with apple proliferation and pear decline. Z. PflKrankh. PflSchutz 91:371-382.

25. Seemüller, E., and Schneider, B. 2004. 'Candidatus Phytoplasma mali', 'Candidatus Phytoplasma pyri', and 'Candidatus phytoplasma prunorum', the causal agents of apple proliferation, pear decline, and European stone fruit yellows, respectively. Int. J. Syst. Evol. Microbiol. 54:1217-1226.

26. Seemüller, E., and Schneider, B. 2007. Differences in virulence and genomic features of 'Candidatus Phytoplasma mali' strains. Phytopathology 97:964-970.

27. Tedeschi, R., and Alma, A. 2004. Transmission of apple proliferation phytoplasma by Cacopsylla melanoneura (Homoptera: Psyllidae). J. Econ. Entomol. 97:8-13 